\title{
analysis
}

\section{Revolution or evolution?}

\author{
A shift to an open-access model of publishing would clearly ben efit science, but who should pay?
}

$\mathrm{T}$ he driving force behind most scientists' careers is to achieve the maximum visibility for their research. Since the creation of the first scientific journals in the mid-seventeenth century, scientists have condensed their data and conclusions into a manuscript and happily handed this over to a publisher, who in return has printed it and distributed it to those willing-or whose institutes are willing - to pay a subscription fee. But the triple whammy of rising journal prices, an exploding number of journals and imploding library budgets means that the bulk of this work can now only be accessed by a small fraction of its intended audience. The arrival of the World Wide Web has the potential to change this reality: now that the vast majority of printed articles are also available in an electronic form, which is theoretically accessible by anyone with an interest and an internet connection, shouldn't all articles become free for everyone to read?

\section{... publishing is still operating largely on an economic model that evolved when there were fewer journals, available only in print}

This reasoning has spawned the 'openaccess' model of publishing, which has been proclaimed as a revolution in science and was the main focus of an EMBL/ EM BO-organized meeting entitled 'Science Publishing at the Crossroads', held on 7 June 2003 at the Print Media Academy in Heidelberg, Germany. Technological advances now enable wider access to scientific literature with no associated distribution costs, but publishing is still operating largely on an economic model that evolved when there were fewer journals, available only in print. Jean-Claude Guédon, a science historian from the University of M ontreal, Canada, concluded his overview of science publishing by saying, "The beauty of science is that it has been the first operational example of how humanity can create a system of distributed intelligence. Right now it's not working in the best possible way with regard to communication. We haven't scaled up so well."

$\Lambda$ round 28,000 scientific periodicals exist at present, and the market for these is incredibly inelastic; most journals and the articles published in them are monopolies, and there is no market correction of prices as a result of competition. If you need an article published in journal $X$, a subscription to journal $Y$ is of no use. In the 1960 s, commercial publishers realized the potential profit to be made in disseminating information, and through their launch of new journals and their control of the core, traditional titles, they have since held a firm grip on scientific communication and the evaluation of scientists. Journal prices have risen dramatically - an institutional subscription to a bundle of seven titles including Brain Research, for example, is US $\$ 20,000$ a year-and publishers are being accused of reaping extortionate profits. Guédon asked, "Is this optimal? Is this the best way to do things for the scientific community?" His answer: no. "Only the wealthiest institutions from the wealthiest countries can afford these things. Brains are being wasted."

In response to this, a number of new initiatives aim to provide everyone in the scientific community and interested members of the public with access to what are, after all, the results of publicly funded research. These include the commercial venture BioMedCentral, which at present publishes 90 open-access journals, the Scholarly Publishing and Academic Resources Coalition (SPARC), the Joint Information Systems Committee and the $O$ pen Society Institute, whose meeting in December 2001 gave rise to the Budapest 0 pen Access Initiative that brought the open-access movement to the forefront. One of the most high-profile organizations, however, is the not-forprofit Public Library of Science (PLOS), co-founded by Harold Varmus, then director of the US National Institutes of Health (NIH), Pat Brown from the Stanford University of Medicine (CA, USA) and Michael Eisen from the U niversity of California at Berkeley, USA. At the meeting Eisen explained, "It's easy to envisage a day when there will be 'Public Libraries of Science' where anybody can go and browse the scientific literature. What we're trying to address is why this obvious common good has not become a reality."

\section{"Weare not just another Nature, Science or Cell. We are morally superior and what we are doing is better for the future of science."}

The current generation of scientists is much more familiar with PubMed and Google than the contents of their library shelves, so it is common for them to stumble across abstracts of articles relevant to their research in journals that would otherwise be outside their core reading. And if their library does not have a subscription to this journal, this not only causes frustration but also inhibits 


\section{science $\&$ society}

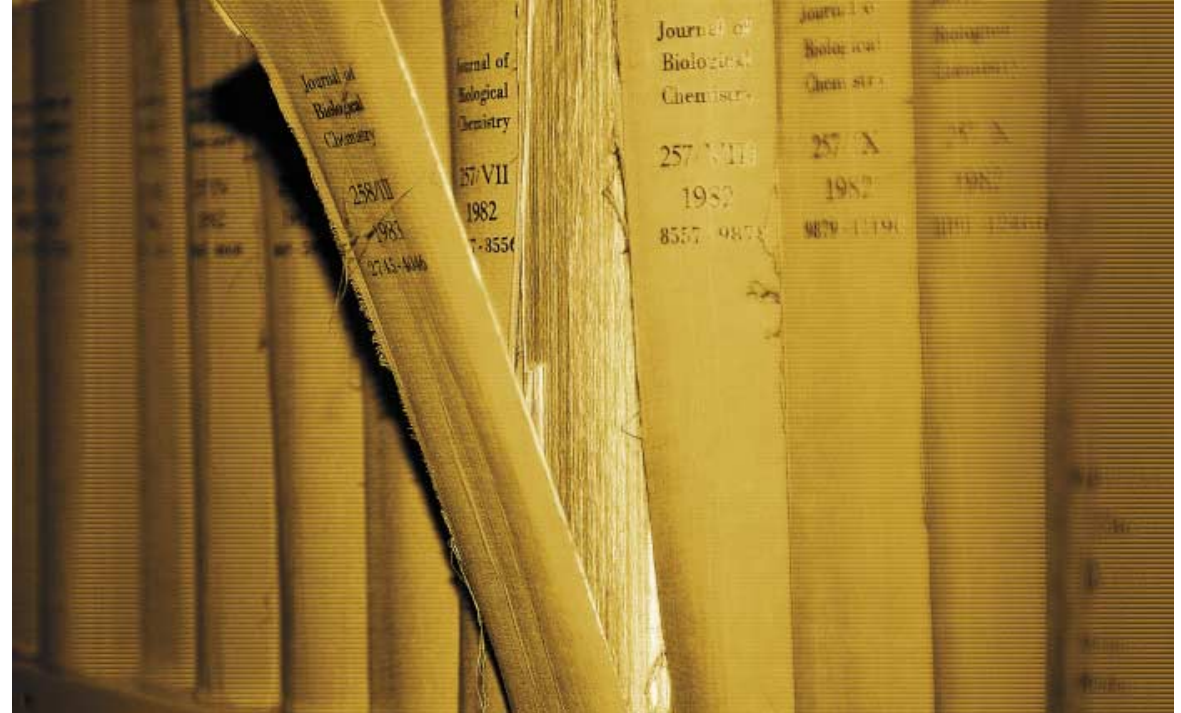

research. The life sciences are now extremely data-driven and a great deal of information needs to be integrated from studies at many different levels: molecular, cellular, organismal and environmental. For progress to be made, this information needs to be freely accessible. Eisen compared the current restrictions on the literature with that of DNA databases such as GenBank. "It is insane that the data itself is made available but the methods that I used and the conclusions that I drew from it are not." Furthermore, he feels that the greatest opportunity that is being wasted is that of enabling scientists to find new and creative ways to use and integrate the literature, which we cannot yet envisage. Eisen said, "We are not just another Nature, Science or Cell. We are morally superior and what we are doing is better for the future of science."

In this current backlash against what are portrayed as greedy, money-grabbing commercial publishers, Elsevier is bearing the brunt of the mudslinging-with more than 1,700 titles and pre-tax profits for 2002 of around $€ 1.5$ billion, they are an obvious target. Varmus recently gave an interview to the German newspaper Die Zeit, and at the mention of Elsevier exclaimed, "That's the devil!" H ow ever, at the meeting, Elsevier's then chief executive, Derk Haank, strongly defended his company's position and outlined the benefits that will come from their transition to electronic publishing. Elsevier have so far digitized 4.4 million scientific articles and aim to have all 8 million articles on the web by the end of next year for all their subscribers to access. "Our end goal is that we want the whole world to have access to our material 24 hours a day with no additional charges to the end user. That is also open access, but it's paid for by the librarian." Haank also outlined their differential pricing scheme, which should make this information accessible to most institutions-those in developing countries have free access, those in intermediate countries and small institutions in the developed world are charged a reduced fee, and only the wealthy, large institutions pay the full subscription. "The important thing to remember is that even in electronic publishing, the costs don't go away. Somebody has to pay," he said. Indeed, the costs of publishing can be significant. A professional editorial office to oversee the reviewing process, editing, and conversion of material to an electronic format are arguably dispensable, but do add to the quality and readability of the final article. Furthermore, Haank noted, "In our experience with electronic publishing, the costs don't go down, they go up. We have to invest in search machines, databases and archiving."

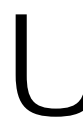

nrestricted access to the literature appears to be a common endgoal, but given the inescapable tion revenue, the question is: who pays? In the open-access model, journals will recoup costs by charging for the service they provide to authors, rather than for costs and the proposed lack of subscrip- content. The original tactic of the PLoS was to convert existing publishers to an open-access model by calling for a boycott of those that operated under a closed-access policy, but this had little effect. "W e've spent far too long hammering on the publishers' doors and telling them that they need to change, but the publishers will only change when we make them change," said Eisen. It was this realization that prompted PLOS to launch two new journals, PLoS Biology and PLoS Medicine, in December 2002, with a US $\$ 9$ million grant from the Gordon and Betty Moore Foundation. The journals' contents will be freely available on the web and the first edition of PLOS Biology is planned for October 2003. Their business model is to charge authors to publish-US $\$ 1,500$ per paper is the current estimate- or to charge institutions a subscription fee, which allows any of their researchers to subsequently publish free of charge. The NIH, Cancer Research UK and all the UK's universities are among the 250 institutions that have signed up so far.

\section{"The important thing to remember is that even in electronic publishing, the costs don't go away. Somebody has to pay"}

The original 'author pays' concept is already being refined to a 'system pays' model, which works on the principle that the money for subscriptions comes from scientists' grants when their institution takes its percentage to fund its library. This money simply needs to be rechannelled, Eisen said. "The question isn't really who pays, it is how we pay. We should view the costs of publication as fundamental costs of doing the research in the first place. They are the last small but critical piece of money we spend as part of the research process. What could be more fundamental than communicating your results to the rest of the community and the public?" In response to this, the Howard Hughes Medical Institute has allocated part of their grants specifically for publication fees, and other funding bodies, such as the NIH, the Max Planck Society and the Wellcome Trust, have endorsed this model. 
$\mathrm{E}$ sen commented "We have given the scientific community this opportunity and now the real question is will the scientific community respond in the way that it should?" But even though these competing open-access journals have been created, the scientists' shift to publishing in them is likely to be slow, most crucially because of the career structures that are in place at present. As long as scientists rely on publishing in high-impact journals to secure funding, there is no incentive to switch to new, open-access models. There needs, therefore, to be changes in the way grantawarding bodies assess performance and in the attitudes of scientists who reinforce the system by aiming to publish only in prestigious journals. In the meantime, however, Frank Gannon, executive director of the EMBO and a senior group leader at the $\mathrm{EMBL}$, warned that "PhD students have their career to make and should not be sacrificed on some altar of idealism."

Furthermore, moving from a subscription-based model may not necessarily suit all journals. There is a high demand for secondary information in the form of reviews and analyses that distill primary data into time-efficient summaries, but journals that feature such articles are particularly labour-intensive and would find it difficult to recoup their costs under the proposed system. Indeed, the only way that journals may be able to protect their subscriptions is by providing content that readers are willing to purchase, possibly in the form of on-line 'knowledge environments' on specific topics of research. Society journals may also find it difficult to move to an open-access model because they rely on the profit from subscriptions to fund other activities. Once the costs of publishing become more transparent, societies will need to find other ways of fundraising to support, for example, their fellowship schemes and conferences. Conversely, open access is

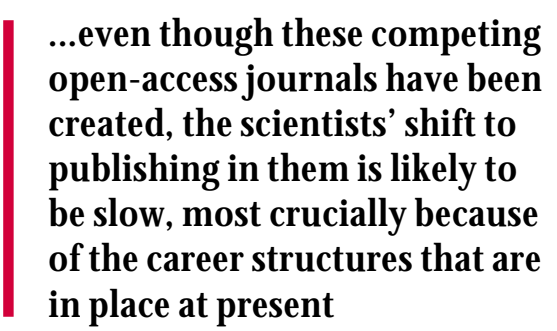

more in line with the mission of societies, in that it maximizes the visibility of research in their field. Sally Morris, secretary general of the Association of Learned and Professional Society Publishers, said: "There is a lot of interest in the model [... ] Society journals are realising that maybe it would be better for their communities." Some journals, including those published by the Company of Biologists and the Society of Endocrinology, are seriously considering moving to the hybrid economic model proposed by David Prosser from SPARC. In what will be an interesting experiment, articles will be available only to subscribers unless the author chooses to pay, in which case they will be freely available on the web. This should demonstrate in the short term whether there is a willingness to pay, and in the longer term whether open access does indeed create increased visibility, and thus citations. "This way there's no risk [for the journals]," said Morris.

Many journals will await the outcome of these trials before committing themselves to open access, particularly given that there are still many question marks over the economics of the model. The true costs will not be apparent for some time as PLoS is at present subsidized by grants, so their eventual author charge is not certain. Also, should journals with high rejection rates pass on all their editorial costs to the authors of accepted papers, or also charge an initial submission fee? The latter is likely to be strongly resisted, as authors already invest significant amounts of time and emotion in each submission without also paying for the experience. If space is unrestricted and economics rule, what is the disincentive for the lower-impact journals to increase their returns by lowering the rejection rate? The result could be an increase in the quantity of scientific articles at the expense of quality. G uédon also speculated that a new market could develop, such that journals are not only competing on impact factors, but also on price. "Will you pay $\$ 1,500$ to PLoS or will you pay $\$ 7,000$ to another publisher given that the money will buy you this branding or that branding? At that point, the battle really starts." And if the institutions that suffer the most under the current subscription model are the poorer ones, nothing will change for them under the open-access model. PLOS will waive the

\section{... an overhaul of the system is perhaps a more complex task than it first appeared when PLoS emerged with their battle cries of revolution}

fee for researchers from developing countries, but those from institutions that do not quite qualify may be excluded from publishing for financial reasons. Gannon said, "We'll be back with another moral dilemma. We have to make countries recognize that it is a tremendously positive investment for them to make the money available such that articles can be published freely."

$\mathrm{T}$ he concept of open-access publishing and the clear benefits that it holds for science are not in debate, but an overhaul of the system is perhaps a more complex task than it first appeared when PLoS emerged with their battle cries of revolution. Many parties have a role to play in the transition, including publishers, funding bodies, societies and of course scientists. At the same time, changes are taking place in the publishing world to improve accessibility without a full-scale break with the systems that are already in place. Journals are being made free to those in the developing world, and many journals are making their content free on the web after a delay of 6-12 months. For some journals, authors now retain the copyright of their work and grant the publishers a 'license to publish'. Differential pricing, as highlighted by Haank, is also important for disseminating information in a more fair and democratic manner. Even if the revolution does not materialize, it will no doubt speed up the evolution of the current pay-per-access model; it is therefore worth taking the time now to work out a system that is optimal. "These new initiatives do have an impact on established parties. I hope that we will indeed move towards [open access] through evolution," Haank concluded. "The only thing that I object to is people destroying what is good about the old system for the sake of destroying it. Let's all move [forward] together."

\section{Susan R. O wens}

doi:10.1038/sj.embor.embor913 